\title{
Nutritional behavior of cyclists during a 24-hour team relay race: a field study report
}

\author{
Raúl Bescós ${ }^{1 *}$, Ferran A Rodríguez¹, Xavier Iglesias', Beat Knechtle², Adolfo Benítez¹, Míchel Marina', \\ Josep M Padullés ${ }^{1}$, Priscila Torrado ${ }^{1}$, Jairo Vazquez ${ }^{1}$ and Thomas Rosemann ${ }^{2}$
}

\begin{abstract}
Background: Information about behavior of energy intake in ultra-endurance cyclists during a 24-hour team relay race is scarce. The nutritional strategy during such an event is an important factor which athletes should plan carefully before the race. The purpose of this study was to examine and compare the nutritional intake of ultraendurance cyclists during a 24-hour team relay race with the current nutritional guidelines for endurance events. Additionally, we analyzed the relationship among the nutritional and performance variables.

Methods: Using a observational design, nutritional intake of eight males (mean \pm SD: $36.7 \pm 4.7$ years; $71.6 \pm 4.9$ kg; $174.6 \pm 7.3 \mathrm{~cm}$; BMI $23.5 \pm 0.5 \mathrm{~kg} / \mathrm{m}^{2}$ ) participating in a 24-hour team relay cycling race was assessed. All food and fluid intake by athletes were weighed and recorded. Additionally, distance and speed performed by each rider were also recorded. Furthermore, before to the race, all subjects carried out an incremental exercise test to determine two heart rate- $\mathrm{VO}_{2}$ regression equations which were used to estimate the energy expenditure.

Results: The mean ingestion of macronutrients during the event was $943 \pm 245 \mathrm{~g}(13.1 \pm 4.0 \mathrm{~g} / \mathrm{kg})$ of carbohydrates, $174 \pm 146 \mathrm{~g}(2.4 \pm 1.9 \mathrm{~g} / \mathrm{kg})$ of proteins and $107 \pm 56 \mathrm{~g}(1.5 \pm 0.7 \mathrm{~g} / \mathrm{kg})$ of lipids, respectively. This amount of nutrients reported an average nutrient intake of $22.8 \pm 8.9 \mathrm{MJ}$ which were significantly lower compared with energy expenditure $42.9 \pm 6.8 \mathrm{MJ}(P=0.012)$. Average fluid consumption corresponded to $10497 \pm 2654 \mathrm{~mL}$. Mean caffeine ingestion was $142 \pm 76 \mathrm{mg}$. Additionally, there was no relationship between the main nutritional variables (i.e. energy intake, carbohydrates, proteins, fluids and caffeine ingestion) and the main performance variables (i.e. distance and speed).
\end{abstract}

Conclusions: A 24-hour hours cycling competition in a team relay format elicited high energy demands which were not compensated by energy intake of the athletes despite that dietary consumption of macronutrients did not differ to the nutritional guidelines for longer events.

Keywords: energy balance, ultra-endurance, macronutrient consumption, hydration, bicycling, weighed dietary record, descriptive study

\section{Background}

Ultra-endurance competitions are defined as endurance performances of more than six hours of duration [1]. Traditionally, ultra-endurance races are held as solo events in attempts to challenge the limits of human endurance. However, the increased popularity of these competitions in recent years has led to different formats of participation, such as team relays with four riders per

\footnotetext{
* Correspondence: raulbescos@gmail.com

'Institut Nacional d'Educació Física de Catalunya, Sports Sciences Research Group, Universitat de Barcelona, Spain

Full list of author information is available at the end of the article
}

team [2]. In comparison with solo events where athletes perform a continuous exercise ( $>6$ hours) at a mean intensity of $\sim 60 \%$ of maximum oxygen uptake $\left(\mathrm{VO}_{2} \mathrm{max}\right)$ [3], team relay competitions elicit intermittent exercise at a mean intensity above $75 \%$ of $\mathrm{VO}_{2} \max [4,5]$.

The nutritional strategy during ultra-endurance events is an important factor that athletes should plan carefully before the race. The amount and the source of energy intake, fluid replacement, as well as the ingestion of stimulants such as caffeine are important factors directly linked to sport performance in endurance events $[6,7]$. In relation with the energy demands, several studies have

\section{() Biomed Central}


assessed the nutritional requirements and behavior of cyclists during solo events [8-10]. However, there is a lack of information about the energy requirements of athletes competing in a team relay. To the best of our knowledge, only one study has estimated the energy expenditure and dietary intake of cyclists during one competition of 24-hour in a team relay format [4]. Surprisingly, this study showed that athletes ingested only $45 \%$ of their estimated energy expenditure during the race. These data are in concordance with results reported in solo riders [8-10] despite that in team relay events, cyclists have a considerable time to recover between the bouts of exercise $[4,5]$.

There is broad evidence that during longer events the energy replacement should be mainly based on food rich in carbohydrate since glycogen stores in the body are limited [11]. This fact could be even more important in intermittent high-intensity competitions such as ultraendurance team relay events where athletes are performing several bouts of exercise at higher intensity with limited recovery period between them. When carbohydrates are not available, or available only in a limited amount, the intensity of exercise must be reduced to a level where the energy requirement can be met by fat oxidation $[7,12]$. The most recent studies in laboratory conditions indicate that the adequate amount of carbohydrate intake to reduce muscle glycogen depletion and optimize carbohydrate oxidation during prolonged exercise is $\sim 1.5 \mathrm{~g} / \mathrm{min}$ [13-15].

Other important issues during ultra-endurance events are both fluid replacement and caffeine ingestion. For instance, it is known that the consumption of beverages containing electrolytes and carbohydrates in a concentration of $6-8 \%$ enhances performance compared to the consumption of plain water [16]. Consumption of caffeine has been also linked to an improved exercise tolerance [17]. Doses of between 1.5 and $3.5 \mathrm{mg} / \mathrm{kg}$ have been found to improve time-trial performances in laboratory studies [18]. The mechanisms to explain benefits of caffeine ingestion are based on an increased utilization of plasma free fatty acids and reduced oxidation of muscle glycogen [19], as well as favorable changes in the central nervous system [20]. However, there is a lack of data indicating the hydration pattern and caffeine consumption followed by cyclists during ultra-endurance team relay competitions.

Accordingly, the primary aims of this study were (1) to describe the dietary energy intake of ultra-endurance cyclists participating in a 24-hour team relay competition, (2) to compare it with the current recommendations for longer events [6,7] and (3) to analyze the correlation between the nutritional intake and the variables of race performance such as completed distance and reached mean speed. We hypothesized that dietary intakes of athletes competing in a 24-hour ultra-endurance cycling race differ to the current nutritional recommendations for longer events, thus, leading to a high energy deficit. Some factors such as appetite suppression and gastrointestinal distress can reduce the dietary intake during longer competitions. In addition, these disturbances can affect the performance of athletes leading to a decrease in performance during the race. This information is needed to expand the limited knowledge of the nutritional behavior of athletes during these types of events, as well as to report new information which could be useful for nutrition professionals to design an adequate nutritional strategy for athletes.

\section{Methods}

\section{Design of the study}

An observational field study at the 24-hour cycle race of Barcelona (Spain) was used for this research. The competition started at 19:00 hrs and consisted of completing the maximum distance possible during the 24-hour period, on a closed road circuit of 3,790 meters in length, and 60 meters of altitude per lap. Within the circuit, all the athletes had a box where they ingested food and performed their relays. The time and average speed of each cyclist was recorded on completion of each lap. The strategy chosen by the athletes during the race was up to them where every team decided the order and duration of the effort. The average temperature during the whole event was $\sim 27.5^{\circ} \mathrm{C}$ (range: $24.6-31.0$ ) and relative humidity was at $\sim 53.9 \%$ (range: $33.0-72.0$ ). The mean velocity of wind was at $\sim 1.7 \mathrm{~m} / \mathrm{s}$ (range: $0.6-3.0$ ).

\section{Subjects}

A total of eight experienced, non-professional, male athletes (6 cyclists and 2 triathletes), voluntarily participated in this study (see Table 1). The athletes were contacted by the researchers via phone between two and three weeks before the race. This race was the first experience in an ultra-endurance team relay cycling event for all athletes. The subjects had $12.9 \pm 8.8$ years of experience in endurance events, and their average weekly training volume was from 15 hours up to a maximum of 30 hours, with a total volume between 800 and 1,000 hours per year. They were all members of the Spanish Cycling or Triathlon Federations and, up to the start of the study, reported no related medical illnesses. All the subjects passed a medical examination and gave their informed written consent, approved by the Ethics Committee of the Catalonian Sports Council, prior to their participation.

\section{Preliminary testing}

One week prior to the competition, all our athletes reported to a physiology laboratory to perform an incremental $\mathrm{VO}_{2}$ max test under controlled conditions $\left(22 \pm 1^{\circ} \mathrm{C}, 40\right.$ $60 \%$ relative humidity, $760-770 \mathrm{mmHg}$ barometric 
Table 1 Physical and physiological characteristics of the subjects

\begin{tabular}{|c|c|c|c|c|c|c|c|c|c|}
\hline Subjects & 1 & 2 & 3 & 4 & 5 & 6 & 7 & 8 & $M \pm S D$ \\
\hline Age (years) & 34.4 & 39.7 & 29.6 & 38.3 & 43.3 & 39.8 & 31.0 & 37.5 & $36.7 \pm 4.7$ \\
\hline Height (cm) & 167.0 & 172.4 & 189.1 & 165.1 & 177.6 & 173.5 & 176.0 & 176.0 & $174.6 \pm 7.3$ \\
\hline Body mass (kg) & 65.3 & 68.9 & 79.9 & 65.7 & 73.9 & 74.5 & 72.5 & 72.4 & $71.6 \pm 4.9$ \\
\hline $\mathrm{BMI}\left(\mathrm{kg} \cdot \mathrm{m}^{2}\right)$ & 23.4 & 23.2 & 22.3 & 24.1 & 23.4 & 24.7 & 23.4 & 23.4 & $23.5 \pm 0.5$ \\
\hline Body fat (\%) & 9.5 & 10.8 & 9.7 & 11.1 & 9.2 & 10.4 & 9.8 & 10.6 & $10.1 \pm 0.7$ \\
\hline $\mathrm{VO}_{\text {2peak }}\left(\mathrm{mL} \cdot \mathrm{kg}^{-1} \cdot \mathrm{min}^{-1}\right)$ & 70.2 & 71.9 & 62.5 & 53.1 & 69.1 & 56.4 & 74.7 & 69.2 & $66.4 \pm 6.8$ \\
\hline$H R_{\max }(b p m)$ & 184 & 165 & 177 & 165 & 178 & 174 & 176 & 176 & $174 \pm 9$ \\
\hline $\mathrm{VT}(\% \mathrm{HR} \max )$ & 72 & 74 & 75 & 83 & 74 & 77 & 80 & 85 & $77 \pm 5$ \\
\hline $\mathrm{RCP}(\% \mathrm{HR} \max )$ & 91 & 89 & 90 & 89 & 91 & 89 & 90 & 92 & $90 \pm 1$ \\
\hline$W_{\text {peak }}\left(W \cdot k g^{-1}\right)$ & 6.1 & 6.2 & 6.3 & 5.7 & 6.4 & 6.0 & 5.5 & 5.9 & $6.0 \pm 0.3$ \\
\hline
\end{tabular}

BMI: body mass index; $\mathrm{VO}_{2 \text { peak }}$ : peak of oxygen uptake; $\mathrm{HR}_{\text {max }}$ : maximum heart rate; $\mathrm{VT}$ : ventilatory threshold expressed as $\%$ of $\mathrm{HR}_{\text {maxi }} \mathrm{RCP}_{\text {: respiratory }}$ compensation point expressed as $\%$ of the maximum heart rate; $W_{\text {peak }}$ : peak of power.

pressure). They were asked to refrain from caffeine, alcohol and heavy exercise on the day before the tests, and to report to the laboratory at least two hours after having eaten. An incremental test was performed on an electronically braked cycle ergometer (Excalibur Sport, Lode, The Netherlands) modified with clip-on pedals. The exercise protocol started at 25 watts $(\mathrm{W})$ and was increased by $25 \mathrm{~W}$ every minute until voluntary exhaustion. The pedaling cadence was individually chosen within the range of 70 - 100 revolutions per minute (rpm). During the test, oxygen uptake $\left(\mathrm{VO}_{2}\right)$, minute ventilation $\left(\mathrm{V}_{\mathrm{E}}\right)$, carbon dioxide production $\left(\mathrm{VCO}_{2}\right)$ and respiratory exchange ratio (RER) were measured, breath-by-breath, using a computerized gas analyzer (Cosmed Quark PFT-Ergo, Italy). Before each test, the ambient conditions were measured and the gas analyzers and inspiratory flowmeter were calibrated using high-precision calibration gases $\left(16.00 \pm 0.01 \% \mathrm{O}_{2}\right.$ and $5.00 \pm 0.01 \%$ $\mathrm{CO}_{2}$, Scott Medical Products, USA). Respiratory data were averaged at $30 \mathrm{~s}$ intervals to determine $\mathrm{VO}_{2}$ max taken as the highest average value. The ventilatory threshold (VT) and the respiratory compensation point (RCP) were measured by three independent reviewers according to methods described by Wasserman et al. [21]. In addition, heart rate was continuously recorded using a portable heart rate monitor (Polar RS800 SD, Finland). Heart rate data were averaged at $10 \mathrm{~s}$ intervals and the maximum heart rate was defined as the heart rate achieved at the point of exhaustion.

\section{Nutritional data}

After the test all the athletes received nutritional guidelines and were encouraged to follow a high carbohydrate diet during the three days prior to the competition in order to optimize their glycogen replenishment. However, during the competition, there were no constraints and the nutritional pattern was programmed by the cyclists themselves. Furthermore, they received no direct instructions from the investigators during the event. Seven trained investigators were divided among the boxes weighing and recording all the food and fluid ingested by each participant during the recovery periods. To weigh all the food, we used two digital scales (Soehnle 8020, Spain) with a precision of $1 \mathrm{~g}$ increments up to $1 \mathrm{~kg}$ and $2 \mathrm{~g}$ between 1 and $2 \mathrm{~kg}$. During the race, it was forbidden to provide to the athletes food and fluids in any point of the circuit with the exception of the box. All the food and fluids that cyclists consumed before every relay were weighed and recorded by the researchers. Immediately after every relay, food and fluids were weighed and recorded by the researchers again. The difference in weight was considered as the amount of food and fluids ingested by the cyclists during exercise. The type of food and fluids of sport products such as energy bars and gels ingested by the cyclists were described and recorded using the labels of the products. Information derived from prepared foods such as pasta, rice or sandwich was provided asking the form of preparation, directly, to the cyclists. The nutritional data was analyzed for nutrient composition using nutritional software. To guarantee a more accurate conversion of energy and nutrient intakes, we used a database of food from the country where the study was carried out (CESNID 1.0, Barcelona University, Spain). Information about the nutritional content of food not available in the computer program was obtained from the manufacturer. We divided the ingestion of energy derived from solid and fluid food (i.e. classified as products that did not need mastication).

Each subject was weighed 30 minutes prior to the race, after every cycle session and immediately after finishing the competition. The subjects were always weighed in clothing, shoes and bicycle helmets in order to facilitate the collection of the research data during the event. Weights were measured on calibrated scales placed on a hard level surface.

\section{Load of exercise and energy expenditure}

During the whole competition, the heart rate was continuously monitored beat-by-beat using portable heart rate monitors (Polar RS800 SD, Finland). Later, all heart 
rate data were averaged at $10 \mathrm{~s}$ intervals. In order to establish a reference for heart rate, we identified three zones of physical exertion based on the VT and the RCP: zone I, below to the VT; zone II, between VT and RCP; and zone III, above RCP. In addition, to estimate the total work load of exercise performed by subjects we used the training impulse (TRIMP) method by Foster et al. [22]. To calculate TRIMP, the score for each heart rate zone was computed by multiplying the accumulated duration in this zone by a multiplier for this particular phase, e.g. $1 \mathrm{~min}$ in zone I was given score of 1 TRIMP $(1 \times 1), 1 \mathrm{~min}$ in zone II was given a score of 2 TRIMP $(1 \times 2)$, and $1 \mathrm{~min}$ in zone III was given a score of 3 TRIMP $(1 \times 3)$. The total TRIMP score was obtained by summating the results of the three zones [ $(\mathrm{min}$ of zone I $\mathrm{HR}[<\mathrm{VT}] \times 1)+($ min of zone II HR $[>\mathrm{VT}-<\mathrm{RCP}] \times$ $2)+($ min of zone III HR $[>\mathrm{RCP}] \times 3)]$.

To estimate energy expenditure during the race, the individually derived linear relationship between heart rate and $\mathrm{VO}_{2}$ was used to estimate the oxygen cost during the work efforts $\left(\mathrm{r}^{2}=0.988 \pm 0.005\right)$. Two different individualized equations were established: 1) a linear regression equation for racing time which was derived from data during the incremental exercise test. We used an energy equivalent of oxygen based on the mean intensity during racing time (i.e. the non-protein energy equivalent corresponding to mean heart rate during the work efforts). This value was, on average, $0.02 \mathrm{MJ} / \mathrm{LO}_{2}(4.970 \pm 0.048 \mathrm{kcal} /$ $\mathrm{LO}_{2}$ ), corresponding to a RER of $0.941 \pm 0.057$ [23]. 2) A single exponential equation best fitted to $\mathrm{VO}_{2}$ and heart rate was taken during the recovery period of the cycle ergometer test $\left(r^{2}=0.912 \pm 0.015\right)$. An energy equivalent of $0.02 \mathrm{MJ} / \mathrm{LO}_{2}\left(4.825 \mathrm{kcal} / \mathrm{LO}_{2}\right)$ was used, assuming a RER of 0.82 [23]. The rationale for our approach was that athletes performed bouts of exercise in which the heart rate$\mathrm{VO}_{2}$ relationship can be assumed to be linear, interspersed with periods of recovery and rest, during which the heart rate- $\mathrm{VO}_{2}$ relationship becomes nonlinear [24].

\section{Statistical analyses}

Data are presented as individual values and means \pm SD. A non-parametric Wilcoxon test was used to compare the energy balance and changes in body mass and exercise intensity during the event. In addition, differences between nutritional data during the first $(1900 \mathrm{~h}-0700 \mathrm{~h})$ and the second (0700 h - 1900 h) 12 hour period were assessed. The main nutritional variables (i.e. energy, carbohydrates, proteins, fats, fluid, sodium and caffeine) were correlated to speed and distance completed in absolute (i.e. $\mathrm{km}$; km/ h) and relative (i.e. \% of decrease of distance and speed) values using Spearman's rank correlation analysis. In addition, fluid and sodium consumption was related to body weight loss. Non-parametric methods were applied, as not all parameters were ideally normally distributed. For all statistical tests, the significance level was set to $P<0.05$. Data were analyzed using SPSS for Windows, version 15.0 (SPSS, Inc, Chicago, Ill).

\section{Results}

\section{Performance during the event}

The main variables controlled during the race are summarized in Table 2. All participants finished the race although two athletes (number 4 and 8 on the Tables 1 to 4) reported gastro-intestinal disturbances during the last hours. All cyclists completed six work efforts, except for two riders who completed seven (subjects number 2 and 5 on the Tables 2 to 5 ). The mean intensity decreased significantly in riders performing six work efforts $\left(1^{\text {st }}\right.$ work effort: $91 \pm 3 \%$ of maximum heart rate [HRmax]; $6^{\text {th }}$ work effort: $86 \pm 4 \%$ of HRmax; $P=0.004)$ and also those completing seven ( $1^{\text {st }}$ work effort: $90 \pm 5 \%$ of HRmax; $7^{\text {th }}$ work effort: $83 \pm 9 \%$ of HRmax; $P=0.002$ ) (Figure 1). The mean cumulative climb during the race was $3168 \pm$ $636 \mathrm{~m}$. The cyclists rested between bouts of exercise for $173.2 \pm 15.6 \mathrm{~min}$.

\section{Macronutrient intake}

Food and fluids rich in carbohydrates were the main source of energy consumed during the event (Table 3). The athletes consumed $395 \pm 193(5.4 \pm 2.6 \mathrm{~g} / \mathrm{kg} ; 42 \pm$ $10 \%$, respectively) and $549 \pm 141 \mathrm{~g}$ of carbohydrates $(7.7 \pm$ $2.1 \mathrm{~g} / \mathrm{kg}$ body mass; $58 \pm 10 \%$, respectively) during the first $(1900-0700 \mathrm{~h})$ and the second $(0700$ - $1900 \mathrm{~h})$ period, respectively. Carbohydrates reported as fluids and solids were $533 \pm 175 \mathrm{~g}(56.8 \pm 10.6 \%)$ and $410 \pm 174 \mathrm{~g}$ (43.2 $\pm 10.6 \%)$, respectively. Protein intake was heterogeneous, while three athletes ingested at rates above $2.5 \mathrm{~g} / \mathrm{kg}$ body mass; the intake of the remaining subjects were below $2.0 \mathrm{~g} / \mathrm{kg}$ body mass. Relative to time, the athletes ingested $92 \pm 90 \mathrm{~g}(1.3 \pm 1.2 \mathrm{~g} / \mathrm{kg}$ body mass; $53 \pm 14 \%$, respectively) of protein during the first half of the event and $82 \pm 52 \mathrm{~g}(1.1 \pm 0.7 \mathrm{~g} / \mathrm{kg}$ body mass; $47 \pm 14 \%$, respectively) during the second. The intake of lipids also differed; four riders showed intake rates below $1.0 \mathrm{~g} / \mathrm{kg}$ and the other four between $1.6 \mathrm{~g} / \mathrm{kg}$ and $2.7 \mathrm{~g} / \mathrm{kg}$, respectively. During the first 12-hour period, the cyclists ingested $59 \pm$ $35 \mathrm{~g}(0.8 \pm 0.5 \mathrm{~g} / \mathrm{kg}$ of body mass; $55 \pm 13 \%$, respectively $)$ of lipid and $48 \pm 31 \mathrm{~g}(0.7 \pm 0.4 \mathrm{~g} / \mathrm{kg}$ of body mass; $45 \pm$ $13 \%$, respectively) during the second period.

\section{Fluid, sodium and caffeine intake}

Total fluid balance and sodium intake are illustrated in Table 4. Overall fluid consumption during the first half of the race $(1900-0700 \mathrm{~h})$ was $4794 \pm 1633 \mathrm{~mL}(46 \pm$ $7 \%)$ and $5703 \pm 1421 \mathrm{~mL}(54 \pm 7 \%)$ during the second $(0700-1900 \mathrm{~h})$, respectively. In relation to racing and recovery time, the cyclists ingested $907 \pm 90$ and $285 \pm$ $128 \mathrm{~mL} / \mathrm{h}$, respectively. Overall fluid consumption 
Table 2 Performance during the event.

\begin{tabular}{|c|c|c|c|c|c|c|c|c|c|}
\hline Subjects & 1 & 2 & 3 & 4 & 5 & 6 & 7 & 8 & Mean \pm SD \\
\hline Racing time (min) & 358 & 406 & 381 & 303 & 495 & 330 & 299 & 318 & $361 \pm 66$ \\
\hline Average intensity (\% HRmax) & 88.4 & 85.3 & 83.7 & 90.8 & 82.4 & 88.1 & 87.5 & 89.8 & $87.0 \pm 2.9$ \\
\hline Time spent in zone I $(\mathrm{min})^{\mathrm{b}}$ & 39 & 30 & 63 & 7 & 81 & 56 & 34 & 78 & $49 \pm 26$ \\
\hline Time spent in zone II (min) ${ }^{b}$ & 207 & 223 & 225 & 89 & 345 & 111 & 140 & 121 & $183 \pm 84$ \\
\hline Time spent in zone III (min) ${ }^{b}$ & 112 & 153 & 93 & 207 & 59 & 163 & 129 & 119 & $129 \pm 45$ \\
\hline TRIMP & 789 & 935 & 792 & 806 & 948 & 767 & 697 & 677 & $801 \pm 98$ \\
\hline Distance (km) & 207 & 223 & 208 & 165 & 282 & 182 & 171 & 163 & $200 \pm 40$ \\
\hline Average speed (km/h) & 34.7 & 33.0 & 32.8 & 32.7 & 34.9 & 33.1 & 33.9 & 30.8 & $33.2 \pm 1.3$ \\
\hline Recovery time (min) & 1082 & 1034 & 1059 & 1137 & 945 & 1110 & 1141 & 1122 & $1079 \pm 66$ \\
\hline
\end{tabular}

: percentage of maximum heart rate; ${ }^{\mathrm{b}}$ : time spent in each zone of exercise intensity during the racing time (zone I: below to the ventilatory threshold; zone II; between the ventilatory threshold and respiratory compensation point; zone III: above to the respiratory compensation point); TRIMP: training impulse.

showed that water $(150 \pm 48 \mathrm{~mL} / \mathrm{h})$ and sports drinks $(139 \pm 91 \mathrm{~mL} / \mathrm{h})$ were the main fluids ingested (Figure 2). The average sodium intake was $1189 \pm 929 \mathrm{mg}(5.2 \pm 2.6$ $\mathrm{mmol} / \mathrm{L}$ of total fluid intake) and $3144 \pm 2128 \mathrm{mg}(17.8 \pm$ $10.2 \mathrm{mmol} / \mathrm{L}$ ) in fluids and solids, respectively. Consumption of sodium increased significantly $(P<0.05)$ during the second period of the competition $(3083 \pm 2020 \mathrm{mg}$; $71 \pm 12 \%$, respectively) compared to the first $(1250 \pm 898$ mg; $29 \pm 12 \%$, respectively). Body mass decreased (3.0 \pm $1.3 \%$ ) significantly over the event (pre-race: $72.0 \pm 4.4 \mathrm{~kg}$; post-race: $69.9 \pm 4.9 \mathrm{~kg} ; P=0.012)$. The loss of body weight during the first $(1900-0700 \mathrm{~h})$ and the second half $(0700-1900 \mathrm{~h})$ of the event was $1.1 \pm 0.9 \mathrm{~kg}$ and $1.9 \pm 0.6 \%(P=0.273)$, respectively. We found no statistical relationship between both fluid intake $(r=0.024 ; P=$ $0.943)$ and sodium intake $(r=0.095 ; P=0.823)$ with body weight loss.

The total consumption of caffeine was $142 \pm 76 \mathrm{mg}$ (2.0 $\pm 1.0 \mathrm{mg} / \mathrm{kg}$ body mass) (Table 4). The consumption

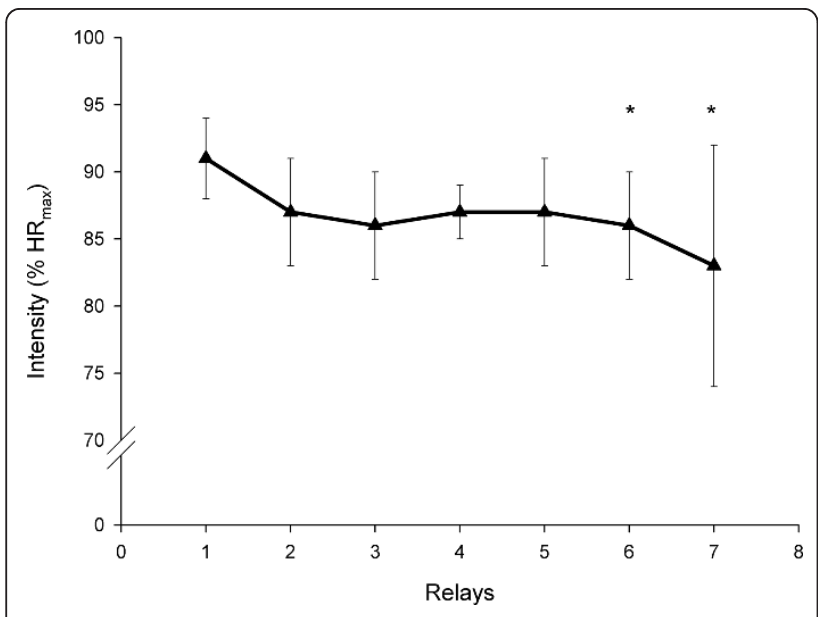

Figure 1 Evolution of the intensity, expressed as \% of maximum heart rate $\left(\mathrm{HR}_{\max }\right)$, during the event. ${ }^{*}$ Statistical difference $(P<0.05)$ mean intensity between the first relay compared with the sixth and seventh relay. of caffeine increased significantly $(P<0.05)$ during the last 12 hour period of the event $(99 \pm 50 \mathrm{mg} ; 1.4 \pm 0.7 \mathrm{mg} / \mathrm{kg}$ body mass) compared with the first 12 hours (43.9 \pm $49.5 \mathrm{mg} ; 0.6 \pm 0.7 \mathrm{mg} / \mathrm{kg}$ body mass). Caffeinated beverages were the main caffeine containing fluids ingested, and smaller amounts of caffeinated drinks, such as Red Bull $^{\circledR}$, coffee, and carbohydrate gels with added caffeine, were ingested by some athletes (Figure 2).

\section{Energy balance}

The individual and mean values of energy intake are summarized in Table 5. Energy intake $(22.8 \pm 8.9 \mathrm{MJ})$ was significantly lower than energy expenditure $(42.9 \pm 6.8 \mathrm{M})$; $P=0.012)$. Thus, a high proportion of energy $(54 \pm 19 \%)$ expended by the athletes was provided from the endogenous fuel stores (Table 5). During the first 12-hour period $(1900-0700 \mathrm{~h}$ ), the athletes consumed $10.8 \pm 5.6 \mathrm{MJ}$ (47 $\pm 7 \%)$ and $12.0 \pm 3.6 \mathrm{MJ}(53 \pm 7 \%)$ during the second period $(0700-1900 \mathrm{~h})$, respectively. Solid foods were the main source of ingested energy reported as $52 \pm 12 \%$ of the total energy intake. The remaining $48 \pm 12 \%$ of ingested energy was supplied by fluids. Energy intake while racing was lower $(3.7 \pm 1.1 \mathrm{MJ} ; 16 \pm 5 \%)$ and derived only from fluids such as hypotonic beverages and gels. The cyclists used mainly the resting periods to ingest food and beverages (19.1 $\pm 7.0 \mathrm{MJ}$; $84 \pm 5 \%)$.

\section{Correlation between nutritional data and performance during the event}

The main performance variables such as distance covered and speed did not correlate to the main nutritional variables such as calories, carbohydrates, fluids and caffeine $(P<0.05)$. In addition, other dietary variables such as intake of proteins, fats and sodium were also not related to performance variables. The strongest correlation was found between cycling speed and total fluid intake $(r=0.71 ; P=0.074)$. When we compared data between the first and the second half of the event, the strongest correlations were found between the total 
Table 3 Macronutrient intake during the event.

\begin{tabular}{|c|c|c|c|c|c|c|c|c|c|}
\hline Subjects & 1 & 2 & 3 & 4 & 5 & 6 & 7 & 8 & Mean $\pm S D$ \\
\hline \multicolumn{10}{|l|}{ Carbohydrates } \\
\hline Solids (g) & 284 & 392 & 290 & 252 & 695 & 323 & 668 & 378 & $533 \pm 175$ \\
\hline Fluids (g) & 538 & 533 & 442 & 566 & 889 & 574 & 456 & 268 & $410 \pm 174$ \\
\hline Total (g) & 822 & 925 & 732 & 818 & 1584 & 897 & 1124 & 647 & $943 \pm 295$ \\
\hline $\mathrm{g} / \mathrm{kg}_{-}^{\mathrm{a}}$ & 12.4 & 13.5 & 9.4 & 12.3 & 21.4 & 11.9 & 15.2 & 8.8 & $13.1 \pm 4.0$ \\
\hline $\mathrm{g} / \mathrm{min}_{-}^{\mathrm{b}}$ & 2.06 & 2.55 & 1.91 & 2.70 & 3.12 & 2.66 & 3.77 & 2.11 & $2.61 \pm 0.62$ \\
\hline$\%_{-}^{c}$ & 77.3 & 80.2 & 76.6 & 81.4 & 62.6 & 64.8 & 67.0 & 59.3 & $71.1 \pm 8.7$ \\
\hline \multicolumn{10}{|l|}{ Protein } \\
\hline Solids (g) & 62 & 66 & 41 & 37 & 262 & 146 & 126 & 128 & $109 \pm 75$ \\
\hline Fluids (g) & 35 & 25 & 35 & 33 & 245 & 80 & 60 & 8 & $65 \pm 76$ \\
\hline Total (g) & 97 & 91 & 76 & 69 & 507 & 226 & 186 & 136 & $174 \pm 146$ \\
\hline $\mathrm{g} / \mathrm{kg}$ & 1.5 & 1.3 & 1.0 & 1.0 & 6.9 & 3.0 & 2.5 & 1.9 & $2.4 \pm 1.9$ \\
\hline$\%$ & 9.2 & 8.0 & 8.1 & 6.9 & 20.2 & 16.1 & 11.2 & 12.7 & $11.5 \pm 4.6$ \\
\hline Ratio CHO: P $(g)_{-}^{d}$ & 8.5 & 10.2 & 9.6 & 11.9 & 3.1 & 4.0 & 6.0 & 4.7 & $7.2 \pm 3.2$ \\
\hline \multicolumn{10}{|l|}{ Lipids } \\
\hline Solids (g) & 47 & 52 & 48 & 37 & 159 & 91 & 142 & 131 & $88 \pm 49$ \\
\hline Fluids (g) & 17 & 10 & 17 & 15 & 42 & 25 & 22 & 5 & $19 \pm 11$ \\
\hline Total (g) & 64 & 62 & 64 & 52 & 201 & 116 & 164 & 136 & $107 \pm 56$ \\
\hline $\mathrm{g} / \mathrm{kg}$ & 1.0 & 0.9 & 0.8 & 0.8 & 2.7 & 1.6 & 2.3 & 1.9 & $1.5 \pm 0.7$ \\
\hline$\%$ & 13.7 & 12.2 & 15.3 & 11.8 & 18.0 & 18.6 & 22.2 & 28.3 & $17.4 \pm 5.6$ \\
\hline
\end{tabular}

a Ratio between total macronutrient intake $(\mathrm{g})$ and body mass $(\mathrm{kg})$ at the beginning of the event.

${ }^{\mathrm{b}}$ Ratio between total carbohydrate intake $(\mathrm{g})$ and total racing time ( $\mathrm{min}$ )

c Percentage of the total energy intake

${ }^{d}$ Ratio CHO: P (g): Ratio of total grams of carbohydrate intake in relation to total grams of protein during the event

fluid intake in $\mathrm{mL} / \mathrm{h}(\mathrm{r}=-0.66 ; P=0.073)$ and $\mathrm{mL}$ of racing time $(\mathrm{r}=-0.66 ; P=0.077)$ with $\%$ of speed decrease during the last 12 hours $(0700-1900 \mathrm{~h})$.

\section{Discussion}

In contrast to our first hypothesis, this study shows that athletes were able to consume amounts of carbohydrates which were in accordance with the current recommendations for longer events [6,7]. However, despite of this fact, these athletes did not meet their energy requirements during the event resulting in a higher energy deficit. The huge workload performed by athletes (TRIMP > 800 ), which was significantly above to data reported in elite cyclists during high mountain stages of the Tour de France ( 600 TRIMP) [25], induced a higher energy expenditure. Thus, these results confirmed partially our preliminary hypotheses and were in agreement with two previous investigations showing that, like solo events, a high energy deficit is common in a team relay format events despite that athletes have considerable time to recover between bouts of exercise [4,26]. One explanation for this effect has been related with appetite suppression since it is known that longer exercise induces a suppression of acylated ghrelin in humans [27]. Ghrelin is an amino acid peptide hormone secreted primarily from cells within the stomach and it has been suggested

Table 4 Fluid, sodium and caffeine intake and body mass loss during the event.

\begin{tabular}{|c|c|c|c|c|c|c|c|c|c|}
\hline Subjects & 1 & 2 & 3 & 4 & 5 & 6 & 7 & 8 & Mean \pm SD \\
\hline \multicolumn{10}{|l|}{ Fluid intake } \\
\hline Racing time $(\mathrm{mL} / \mathrm{h})$ & 923 & 821 & 854 & 888 & 911 & 841 & 1110 & 905 & $907 \pm 90$ \\
\hline Recovery time $(\mathrm{mL} / \mathrm{h})$ & 291 & 352 & 94 & 283 & 522 & 316 & 261 & 163 & $285 \pm 128$ \\
\hline Total $(\mathrm{mL})$ & 11185 & 11293 & 7106 & 9850 & 15831 & 10535 & 10480 & 7699 & $10497 \pm 2654$ \\
\hline \multicolumn{10}{|l|}{ Sodium } \\
\hline Fluids (mg) & 911 & 897 & 518 & 767 & 3,321 & 1,682 & 678 & 738 & $1189 \pm 929$ \\
\hline Solids (mg) & 2466 & 2240 & 981 & 1583 & 6424 & 1357 & 4027 & 6073 & $3144 \pm 2128$ \\
\hline Total (mg) & 3377 & 3137 & 1499 & 2350 & 9745 & 3039 & 4705 & 6811 & $4333 \pm 2714$ \\
\hline Body mass loss (kg) & 2.8 & 1.4 & 1.3 & 2.5 & 2.3 & 3.0 & 0.8 & 3.2 & $3.0 \pm 1.3$ \\
\hline Caffeine (mg/kg) & 2.0 & 2.7 & 2.4 & 1.2 & 3.4 & 0.1 & 2.5 & 1.5 & $2.0 \pm 1.0$ \\
\hline
\end{tabular}




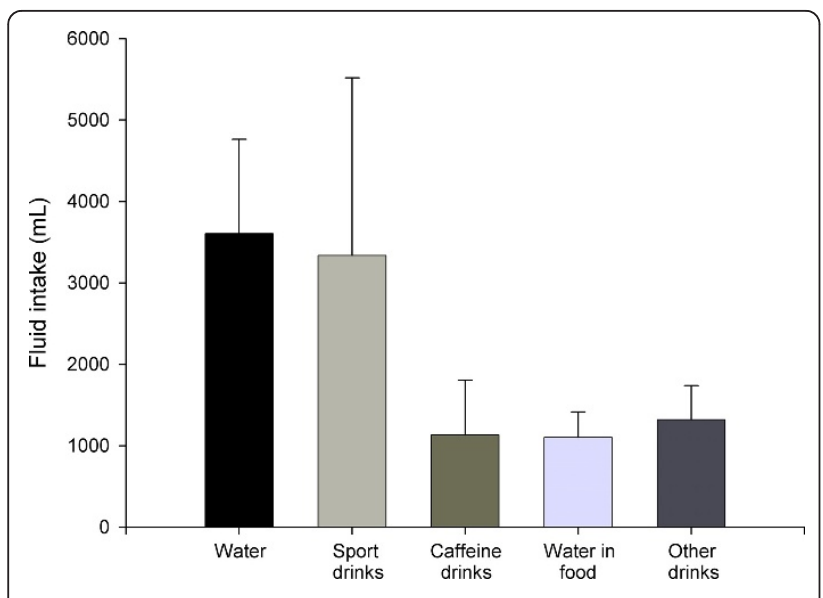

Figure 2 Main fluids used for hydration and their average consumption during the event.

to have an orexigenic function (i.e. appetite stimulating) [27].

\section{Macronutrients intake}

The recommended amount of carbohydrate intake during longer exercise to optimize oxidation rates have been reported as between 1.0 to $1.5 \mathrm{~g} / \mathrm{min}$ [15]. This recommendation could be also useful to improve glycogen replenishment during the first 4 hours after exercise [28]. In the current study, the mean carbohydrate intake in relation to total racing time $(2.61 \pm 0.62 \mathrm{~g} / \mathrm{min})$ was substantially above these values. Moreover, the relative amount of carbohydrate intake by cyclists was equivalent to $13.1 \pm$ $4.0 \mathrm{~g} / \mathrm{kg}$ of body mass. This data reflects the recommendations for extremely prolonged and intense exercise (10$12 \mathrm{~g} / \mathrm{kg}$ of body mass/day) [11]. These findings show that ultra-endurance athletes competing in team relay format can reach the consumption of carbohydrates which has been suggested in a laboratory study to optimize carbohydrate oxidation [13]. This fact is very important in ultraendurance team relay events, since athletes can perform more than $80 \%$ of racing time at intensities corresponding to zone II and III of $\mathrm{HR}_{\max }$ (Table 2). It is known that this pattern of exercise elicits an important oxidation of carbohydrates as a main fuel for muscle contraction [12].

Nevertheless, not only is the amount of carbohydrates important, it should be also paid attention on other factors relating to the limitations of carbohydrate absorption. The feeding schedule, particle size, meal temperature, osmolality and exercise intensity determine the gastric emptying and absorption in the duodenum [29]. For instance, some studies have demonstrated that a homogenized fluid meal, rich in carbohydrates, empties substantially faster than an equivalent solid meal $[29,30]$. However, in longer events, solid food will satisfy an athlete's hunger and allow for more variation, which can also help to intake adequate amounts of carbohydrates [1]. In this study the source of energy was balanced between solids $(2,877 \pm 1,355 \mathrm{kcal})$ and fluids $(2,560 \pm 1,074)$, respectively.

In addition, there is evidence that during high-intensity exercise ( $>80 \% \mathrm{VO}_{2}$ max) a reduced blood flow to the gut may result in a decreased absorption of both glucose and water [31]. In the current study, two cyclists evidenced gastro-intestinal disturbances related to nausea, abdominal cramps and diarrhea during the last hours of the event. Interestingly, both cyclists performed relays at high intensity compared with the other cyclists (subject's number 4 and 8 in Table 2). Taking in account that blood flow to the gut decreases in proportion to the exercise intensity and gastro-intestinal problems are more likely to occur when the exercise intensity is increased [23], this fact could be an explanation for the occurrence of these problems. However, this is only speculation and we cannot

Table 5 Energy balance during the event.

\begin{tabular}{|c|c|c|c|c|c|c|c|c|c|}
\hline Subjects & 1 & 2 & 3 & 4 & 5 & 6 & 7 & 8 & Mean \pm SD \\
\hline \multicolumn{10}{|l|}{ El during racing time $(\mathrm{MJ})^{\mathrm{a}}$} \\
\hline Fluids & 2.5 & 3.1 & 3.1 & 2.6 & 5.9 & 4.7 & 3.7 & 3.9 & $3.7 \pm 1.1$ \\
\hline Solids & 7.6 & 9.6 & 7.6 & 6.2 & 22.0 & 11.3 & 18.7 & 13.4 & $12.1 \pm 5.7$ \\
\hline Fluids & 7.7 & 6.6 & 5.4 & 8.0 & 14.7 & 7.1 & 5.7 & 0.9 & $7.0 \pm 3.8$ \\
\hline Total Energy Intake & 17.8 & 19.3 & 16.1 & 16.8 & 42.6 & 23.1 & 28.1 & 18.2 & $22.8 \pm 8.9$ \\
\hline \multicolumn{10}{|l|}{ Energy expenditure (MJ) } \\
\hline Racing time & 32.6 & 30.1 & 34.3 & 22.1 & 40.1 & 25.5 & 22.5 & 22.8 & $28.8 \pm 6.6$ \\
\hline Recovery time & 13.4 & 13.9 & 20.0 & 13.0 & 9.4 & 14.2 & 14.5 & 15.6 & $14.3 \pm 2.9$ \\
\hline Total Energy Expenditure & 46.0 & 44.0 & 54.3 & 35.1 & 49.5 & 39.7 & 36.0 & 38.4 & $42.9 \pm 6.8^{*}$ \\
\hline Energy Deficit (MJ) & -28.2 & -24.7 & -38.2 & -18.3 & -6.9 & -16.6 & -7.9 & -20.2 & $-20.1 \pm 10.4$ \\
\hline $\mathrm{El}^{\mathrm{EE}} \mathrm{E}_{-}^{\mathrm{b}}$ & 0.39 & 0.44 & 0.30 & 0.48 & 0.86 & 0.58 & 0.76 & 0.47 & $0.54 \pm 0.19$ \\
\hline
\end{tabular}

\footnotetext{
${ }^{a}$ Energy intake

${ }^{\mathrm{b}}$ Ratio between energy intake and energy expenditure.

* Statistical difference $(P<0.05)$ between total energy intake and energy expenditure during the event.
} 
exclude other important factors that may also increase the risk of gastro-intestinal disturbances. For instance, an interesting finding of this study was that fluid yogurt represented the third highest energy contribution in the diet of the cyclists (Table 6). Although the ingestion of milk and derived products just after exercise has been suggested to be an excellent dietary form to attenuate whole body protein breakdown [32], there is also evidence indicating that the consumption of such products could be associated with greater satiety and reduced ad libitum energy intake in humans [33]. It seems that this effect is related with the presence of casein proteins in milk [34]. Thus, although the consumption of milk or derived products like liquid yogurt could be an easy form to enhance recovery processes after bouts of exercise during team relay event, it should be taking in account that they can decrease gastric emptying and be a risk for intestinal disorders. To avoid these problems, we recommend that athletes need to practice their dietary strategy before the event testing the tolerance of all products that they will use during the race. In addition, like muscle skeletal adaptations induce by physical training, adequate nutritional training -ingestion of small and frequent amounts of food and fluids during exercise- may induce adaptations of the digestive system and reduce the risk of gastro-intestinal distress [31].

Regarding protein recommendations (1.2 to $1.7 \mathrm{~g} / \mathrm{kg}$ of body mass/day) [11], we found that almost all athletes consumed an adequate amount of this macronutrient. However, although protein is not an essential substrate used to provide energy, it could play an important role

Table 6 Main food and beverages sources of energy and nutrients during the event.

\begin{tabular}{ll}
\hline Food & $\begin{array}{l}\text { Energy contribution } \\
\mathbf{( \% )}\end{array}$ \\
\hline $\begin{array}{l}\text { Pasta and rice (with tomato or oil olive and } \\
\text { cheese) }\end{array}$ & 25.0 \\
Sport drinks & 13.8 \\
Fluid yogurt & 12.3 \\
Caffeinated drinks (Cola and Red Bull) & 8.5 \\
Fruits (Banana, apple, peach and pear) & 5.6 \\
Cakes & 5.1 \\
Meat (Chicken and ham) & 4.6 \\
Sport Bars & 4.1 \\
Sport Gels & 3.6 \\
Bread & 3.3 \\
Fruit juice & 2.9 \\
Dried fruits (almonds and nuts) & 2.2 \\
Cereals & 2.0 \\
Milk & 1.9 \\
Tuna & 0.4 \\
Others (protein supplements, coffee, soy milk, & 4.7 \\
sugar, etc) & \\
\hline
\end{tabular}

during longer events. Several studies have suggested that a carbohydrate/protein ratio around 4:1 can enhance glycogen recovery, as well as protein balance, tissue repair and adaptations involving synthesis of new protein $[35,36]$. These findings are interesting for ultraendurance athletes competing in team relay events because the nutritional goal of them is to promote and accelerate the recovery of their endogenous glycogen stores and fluid replenishment after every work effort. However, the ingestion of carbohydrate/protein ratio of 4:1 in competition like the current event induces higher protein consumption. For example, applying this ratio to this study, it was estimated that adequate protein consumption would have to be $\sim 236 \mathrm{~g}(\sim 3.6 \mathrm{~g} / \mathrm{kg}$ body mass). In the present study, only two cyclists were able to consume amounts of protein like this. Furthermore, apart of these supposed benefits of carbohydrate and protein combination, it should be also taken in account that protein intake is associated with greater satiety and a reduced ad libitum energy intake in humans [33]. Therefore, further studies are needed to analyze whether an increase of protein intake above the current recommendations (1.2 to $1.7 \mathrm{~g} / \mathrm{kg}$ of body mass/day) may induce benefits in longer and high-intensity sport events.

Lastly, fat intake in these athletes was low in comparison with previous studies involving also cyclists during team relay events [26]. This fact, clearly, contributed to increase the negative energy balance showed in this study. However, contrary to carbohydrates, there is no evidence indicating that the increase of fat intake improves exercise performance [37]. The stores of fat in the human body are so large and they will not become depleted after prolonged events such as 24-hour competitions [38]. Thus, there is no evidence to justify that the current cyclists would increase the amount of fat intake during the event. Nevertheless, the inclusion of fat in the diet of ultra-endurance events could be interesting, not to provide caloric dense options, but to satisfy the taste of foods [1].

\section{Fluid balance and caffeine intake}

The volume of fluid ingestion during bouts of exercise was in accordance with the recommendations for longer events [16]. However, the composition of fluids was not in accordance with these guidelines [16]. While these riders ingested high amounts of water, they should have prioritized the consumption of hypotonic fluids containing carbohydrates, such as sucrose, maltose or maltodextrin at $\sim 3-8 \%$ weight/volume, and sodium concentration of between 30 and $50 \mathrm{mmol} / \mathrm{L}$ [39]. The consumption of these beverages is interesting in order to reduce dehydration and weight losses. In this study, the body mass of the riders decreased significantly after the race being this reduction more important in the second half of the event 
compared with the first 12 hours. However, it is worth to mention that all body mass reduction cannot be related to fluid losses, since we found no relationship between body weight losses and fluid ingestion. From this viewpoint, there is evidence that other factors such as loss of fat mass, skeletal muscle mass, glycogen and water stored in glycogen could also account for at least $2 \mathrm{~kg}$ of body mass loss $[40,41]$. Thus, and according to the high energy deficit in the present cyclists, it could be also suggested that a considerable amount of body weight loss was derived from losses of their endogenous energy stores. Unfortunately, we did not record urine output during the study. These data might have provided more detailed information about fluid balance and the origin of body weight loss. In addition, the use of sweat patches could be very interesting to analyze electrolyte losses in future investigations.

Products rich in caffeine such as caffeinated beverages, coffee and caffeinated sport gels were consumed especially during the second half of the event when fatigue symptoms were more pronounced. Doses of caffeine between 1.5 and $3.5 \mathrm{mg} / \mathrm{kg}^{-1}$ body mass have been reported to enhance power output in laboratory studies [18]. Although, caffeine has been also linked to diuretic effects [42], it seems that moderate doses $(<460 \mathrm{mg})$ of caffeine, do not induce water and electrolyte imbalance or hyperthermia [42]. In this study, all the subjects consumed amounts of caffeine below this threshold during the event.

\section{Relationship between nutritional data and performance during the event}

In the present study, we found no correlation between the main nutritional variables (i.e. energy, carbohydrates, fluids and caffeine) and performance (i.e. completed distance or mean cycling speed) during the event. The strongest relationship was found between total fluid intakes and cycling speed. This fact can add support to the wide scientific evidence indicating that in hot environmental conditions, such as in the current event, a careful hydration strategy is one of the key fundamentals to maintain the athletic performance $[16,39]$.

\section{Strength and limitations of the present study}

A major strength of this study is the careful nutritional analysis which was carried out in a community and setting where little information has been forthcoming. We were able to weigh and record all foods and fluids ingested by the eight athletes in a real competition. This methodology is not easy to apply in the field, but reports more reliable information compared to questionnaires or dietary surveys which have been employed in other previous investigations $[9,10,43,44]$. However, we should also acknowledge some limitations and caveats in this study. Perhaps, the main limitation was the sample size, which was small to analyze the relationship between nutritional and performance variables. In addition, although the relationship between heart rate- $\mathrm{VO}_{2}$ has been shown to be an acceptable measure for estimating energy expenditure during non-steady state $[45,46]$, it should be admitted that this methodology can be affected by several physiological and environmental factors such as dehydration and temperature [47]. Currently, doubly-labeled water is considered to be the gold standard method for estimating energy expenditure in free living humans, which can also be used under field conditions, but it is an expensive method. On the contrary, the heart rate- $\mathrm{VO}_{2}$ regression equation is a feasible and reasonably priced method which has been employed in other previous investigations $[43,48,49]$.

\section{Conclusions}

Cycling ultra-endurance events lasting 24-hour in a team relay format elicits several bouts of exercise, with limited recovery between them, at high exercise intensity (> 75\% of $\mathrm{VO}_{2} \mathrm{max}$ ). This pattern of exercise stimulates an important consumption of carbohydrates to supply energy for muscle contraction. This study shows that these ultra-endurance athletes were able to consume large amount of carbohydrates in a field competition which was in accordance with data obtained in laboratory studies in order to optimize carbohydrate oxidation during exercise. However, despite of this fact we found an increased energy deficit throughout the race. This finding indicates that the nutritional pattern followed the days before to the competition could be even, or at least, as important that the dietary strategy during the event. In addition, although protein ingestion by athletes was in accordance with the current recommendations for athletes, it has been suggested that carbohydrate/ protein ratio of $4: 1$ can enhance several metabolic processes such as glycogen recovery, protein balance and tissue repair which can affect the overall performance. Nevertheless, while the accomplishment of this ratio could induce these benefits and reduce the energy deficit it is unknown whether athletes can tolerate high protein ingestion and perform high intensity exercise without gastro-intestinal disturbances. To avoid these problems, it is very recommendable that athletes perform a nutritional training before to the event ingesting small and frequent amounts of macronutrients and fluids during training sessions. This training may enhance the response of the digestive system during ultra-endurance events and reduce the risk of gastrointestinal distress during longer events in hard environment conditions.

\section{Acknowledgements}

The present study was funded by the National Institute of Physical Education (INEFC) and by the University of Zürich (Switzerland). The authors 
gratefully acknowledge the participation of the athletes in this study and the generous support of Polar Ibérica (Spain), RPM Events, and Research Group of Applied Nutrition, Department of Nutrition and Bromatology (University of Barcelona). We are indebted to Dave Clamp for his editorial assistance. We would also like to thank Víctor Cervera for his technical support.

\section{Author details}

'Institut Nacional d'Educació Física de Catalunya, Sports Sciences Research Group, Universitat de Barcelona, Spain. ${ }^{2}$ Institute of General Practice and for Health Services Research, University of Zurich, Switzerland.

\section{Authors' contributions}

$\mathrm{RB}$, participated in the design of the study, managed the data collection process, conducted the analysis and drafted the manuscript. FR and XI, participated in the design of the study and managed the data collection process. AB, MM, JP, PT and JV participated in the data collection process. BK and TR supervised the analyses of data and helped to draft the manuscript. All authors read and approved the final manuscript.

\section{Competing interests}

The authors declare that they have no competing interests.

Received: 11 August 2011 Accepted: 6 February 2012

Published: 6 February 2012

\section{References}

1. Zaryski C, Smith DJ: Training principles and issues for ultra-endurance athletes. Curr Sports Med Rep 2005, 4:165-170.

2. Laursen PB, Rhodes EC: Physiological analysis of a high intensity ultraendurance event. Strength \& Conditioning Journal 1999, 21:26.

3. Neumayr G, Pfister R, Mitterbauer G, Gaenzer H, Sturm W, Hoertnagl H: Heart rate response to ultraendurance cycling. Br I Sports Med 2003, 37:89-90.

4. Laursen PB, Ahern SM, Herzig PJ, Shing CM, Jenkins DG: Physiological responses to repeated bouts of high-intensity ultraendurance cycling-a field study case report. J Sci Med Sport 2003, 6:176-186.

5. Bescós R, Rodriguez FA, Iglesias X, Knechtle B, Benítez A, Marina M, Padulles JM, Vazquez J, Torrado P: Physiological demands of cyclists during an ultra-endurance relay race: a field study report. Chin J Physiol 2011, 54:339-346.

6. Laursen $\mathrm{PB}$, Rhodes EC: Factors affecting performance in an ultraendurance triathlon. Sports Med 2001, 31:195-209.

7. Peters EM: Nutritional aspects in ultra-endurance exercise. Curr Opin Clin Nutr Metab Care 2003, 6:427-434.

8. White JA, Ward C, Nelson H: Ergogenic demands of a 24 hour cycling event. Br J Sports Med 1984, 18:165-171.

9. Havemann L, Goedecke JH: Nutritional practices of male cyclists before and during an ultraendurance event. Int I Sport Nutr Exerc Metab 2008, 18:551-566.

10. Knechtle B, Enggist $A$, Jehle $T$ : Energy turnover at the Race Across AMerica (RAAM) - a case report. Int J Sports Med 2005, 26:499-503.

11. Rodriguez NR, Di Marco NM, Langley S: American College of Sports Medicine position stand. Nutrition and athletic performance. Med Sci Sports Exerc 2009, 41:709-731.

12. Romijn J, Coyle E, Sidossis L, Gastaldelli A, Horowitz J, Endert E, Wolfe RR: Regulation of endogenous fat and carbohydrate metabolism in relation to exercise intensity and duration. Am J Physiol Endoncrinol Metab 1993, 265:380-391.

13. Pfeiffer B, Stellingwerff $T$, Zaltas $E$, Hodgson AB, Jeukendrup AE: Carbohydrate oxidation from a drink during running compared with cycling exercise. Med Sci Sports Exerc 2011, 43:327-334.

14. Wallis GA, Rowlands DS, Shaw C, Jentjens RL, Jeukendrup AE: Oxidation of combined ingestion of maltodextrins and fructose during exercise. Med Sci Sports Exerc 2005, 37:426-432.

15. Jeukendrup AE, Moseley L, Mainwaring Gl, Samuels S, Perry S, Mann CH: Exogenous carbohydrate oxidation during ultraendurance exercise. $J$ Appl Physiol 2006, 100:1134-1141

16. Sawka MN, Burke LM, Eichner ER, Maughan RJ, Montain SJ, Stachenfeld NS: American College of Sports Medicine position stand. Exercise and fluid replacement. Med Sci Sports Exerc 2007, 39:377-390.
17. Imagawa TF, Hirano I, Utsuki K, Horie M, Naka A, Matsumoto K, Imagawa S: Caffeine and taurine enhance endurance performance. Int I Sports Med 2009, 30:485-488.

18. Cox GR, Desbrow B, Montgomery PG, Anderson ME, Bruce CR, Macrides TA, Martin DT, Moquin A, Roberts A, Hawley JA, Burke L: Effect of different protocols of caffeine intake on metabolism and endurance performance. J Appl Physiol 2002, 93:990-999.

19. Spriet LL, MacLean DA, Dyck DJ, Hultman E, Cederblad G, Graham TE: Caffeine ingestion and muscle metabolism during prolonged exercise in humans. Am J Physiol 1992, 262:891-898.

20. Tarnopolsky MA: Effect of caffeine on the neuromuscular systempotential as an ergogenic aid. Appl Physiol Nutr Metab 2008, 33:1284-1289.

21. Wasserman K, Hansen JE, Sue DY, Stringer WW, Whipp BJ: Principles of exercise testing and interpretation Lippincott Williams and Wilkins. Philadelphia; 2004

22. Foster C, Florhaug JA, Franklin J, Gottschall L, Hrovatin LA, Parker S, Doleshal P, Dodge C: A new approach to monitoring exercise training. $J$ Strength Cond Res 2001, 15:109-115.

23. Zuntz N: Ueber die bedeutung der verschiedenen nahrstoffe als erzeuger der muskelkraft. Pflugers Archiv Eur J Physiol 1901, 83:557-571.

24. Li R, Deurenberg P, Hautvast JG: A critical evaluation of heart rate monitoring to assess energy expenditure in individuals. Am J Clin Nutr 1993, 58:602-607.

25. Lucia A, Hoyos J, Santalla A, Earnest C, Chicharro JL: Tour de France versus Vuelta a Espana: which is harder? Med Sci Sports Exerc 2003, 35:872-878.

26. Hulton AT, Lahart I, Williams KL, Godfrey R, Charlesworth S, Wilson M, Pedlar C, Whyte G: Energy expenditure in the Race Across America (RAAM). Int J Sports Med 2010, 31:463-467.

27. Broom DR, Stensel DJ, Bishop NC, Burns SF, Miyashita M: Exercise-induced suppression of acylated ghrelin in humans. J Appl Physiol 2007, 102:2165-2171.

28. Burke LM, Kiens B, Ivy JL: Carbohydrates and fat for training and recovery. J Sports Sci 2004, 22:15-30.

29. Brouns F, Saris WH, Rehrer NJ: Abdominal complaints and gastrointestinal function during long-lasting exercise. Int J Sports Med 1987, 8:175-189.

30. Rehrer NJ, Brouns F, Beckers EJ, ten Hoor F, Saris WH: Gastric emptying with repeated drinking during running and bicycling. Int I Sports Med 1990, 11:238-43.

31. Brouns F, Beckers E: Is the gut an athletic organ? Digestion, absorption and exercise. Sports Med 1993, 15:242-257.

32. Roy BD: Milk: the new sports drink? A Review. J Int Soc Sports Nutr 2008, $5: 15$.

33. Bowen J, Noakes M, Trenerry C, Clifton PM: Energy intake, ghrelin, and cholecystokinin after different carbohydrate and protein preloads in overweight men. J Clin Endocrinol Metab 2006, 91:1477-1483.

34. Hall WL, Millward DJ, Long SJ, Morgan LM: Casein and whey exert different effects on plasma amino acid profiles, gastrointestinal hormone secretion and appetite. Br J Nutr 2003, 89:239-248.

35. Koopman R, Pannemans DL, Jeukendrup AE, Gijsen AP, Senden JM, Halliday D, Saris WH, van Loon LJ, Wagenmakers AJ: Combined ingestion of protein and carbohydrate improves protein balance during ultraendurance exercise. Am J Physiol Endocrinol Metab 2004, 287:712-720.

36. Ferguson-Stegall L, McCleave EL, Ding Z, Kammer LM, Wang B, Doerner PG, Liu Y, Ivy JL: The effect of a low carbohydrate beverage with added protein on cycling endurance performance in trained athletes. J Strength Cond Res 2010, 24:2577-2586.

37. Vogt M, Puntschart A, Howald H, Mueller B, Mannhart C, Gfeller-Tuescher L, Mullis $\mathrm{P}$, Hoppeler $\mathrm{H}$ : Effects of dietary fat on muscle substrates, metabolism, and performance in athletes. Med Sci Sports Exerc 2003, 35:952-960.

38. Knechtle B, Muller G, Willmann F, Kotteck K, Eser P, Knecht H: Fat oxidation in men and women endurance athletes in running and cycling. Int $J$ Sports Med 2004, 25:38-44.

39. Rehrer NJ: Fluid and electrolyte balance in ultra-endurance sport. Sports Med 2001, 31:701-715.

40. Speedy DB, Noakes TD, Kimber NE, Rogers IR, Thompson JM, Boswell DR, Ross JJ, Campbell RG, Gallagher PG, Kuttner JA: Fluid balance during and after an ironman triathlon. Clin J Sport Med 2001, 11:44-50.

41. Knechtle B, Baumann B, Wirth A, Knechtle P, Rosemann T: Male ironman triathletes lose skeletal muscle mass. Asia Pac J Clin Nutr 2010, 19:91-97. 
42. Armstrong LE, Casa DJ, Maresh CM, Ganio MS: Caffeine, fluid-electrolyte balance, temperature regulation, and exercise-heat tolerance. Exerc Sport Sci Rev 2007, 35:135-140.

43. Bourrilhon C, Philippe M, Chennaoui M, Van Beers P, Lepers R, Dussault C, Guezennec CY, Gomez-Merino D: Energy expenditure during an ultraendurance alpine climbing race. Wilderness Environ Med 2009, 20:225-233.

44. Colombani P, Mannhart C, Wenk C, Frey W: Nutritional intake during 244 km multisport ultraendurance race. Pakistan I Nutr 2002, 1:124-126.

45. Bot SD, Hollander AP: The relationship between heart rate and oxygen uptake during non-steady state exercise. Ergonomics 2000, 43:1578-1592.

46. Dugas $L R$, van der Merwe $L$, Odendaal $H$, Noakes TD, Lambert EV: A novel energy expenditure prediction equation for intermittent physical activity. Med Sci Sports Exerc 2005, 37:2154-2161.

47. Hiilloskorpi H, Fogelholm M, Laukkanen R, Pasanen M, Oja P, Manttari A, Natri A: Factors affecting the relation between heart rate and energy expenditure during exercise. Int J Sports Med 1999, 20:438-443.

48. Bircher S, Enggist A, Jehle T, Knechtle B: Effects of an extreme endurance race on energy balance and body composition - a case study. J Sports Sci Med 2006, 5:154-162.

49. Stewart IB, Stewart KL: Energy balance during two days of continuous stationary cycling. J Int Soc Sports Nutr 2007, 4:15.

doi:10.1186/1550-2783-9-3

Cite this article as: Bescós et al: Nutritional behavior of cyclists during a 24-hour team relay race: a field study report. Journal of the International Society of Sports Nutrition 2012 9:3.

\section{Submit your next manuscript to BioMed Central and take full advantage of:}

- Convenient online submission

- Thorough peer review

- No space constraints or color figure charges

- Immediate publication on acceptance

- Inclusion in PubMed, CAS, Scopus and Google Scholar

- Research which is freely available for redistribution

Submit your manuscript at www.biomedcentral.com/submit 